\title{
BM] Global Health Relapses of Plasmodium vivax malaria threaten disease elimination: time to deploy tafenoquine in India?
}

\author{
Sundus Shafat Ahmad, ${ }^{1}$ Manju Rahi, ${ }^{2}$ Amit Sharma (1) ${ }^{1}$
}

\begin{abstract}
To cite: Ahmad SS, Rahi M, Sharma A. Relapses of Plasmodium vivax malaria threaten disease elimination: time to deploy tafenoquine in India? BMJ Global Health 2021;6:e004558. doi:10.1136/ bmjgh-2020-004558
\end{abstract}

Handling editor Seye Abimbola

Received 25 November 2020 Revised 30 January 2021 Accepted 2 February 202

\section{Check for updates}

(c) Author(s) (or their employer(s)) 2021. Re-use permitted under CC BY-NC. No commercial re-use. See rights and permissions. Published by BMJ.

${ }^{1}$ Parasite and Host Biology, National Institute of Malaria Research, New Delhi, Delhi, India

${ }^{2}$ Epidemiology and Communicable Diseases, Indian Council of Medical Research, New Delhi, Delhi, India

Correspondence to Dr Amit Sharma; directornimr@gmail.com

\section{INTRODUCTION}

Millions suffer from the scourge of malaria across the world, reflected by the estimated 228 million cases and 0.4 million deaths it caused in 2018, as reported in the World Malaria Report 2019. India and African nations shouldered $85 \%$ of the world's malaria burden in 2018. The South-East Asia Region recorded a $70 \%$ decrease in malaria incidence from 2010 (17 cases/1000 population) to 2018 (5 cases/1000 population). Despite the absolute reduction in India's malaria cases, with 2.6 million fewer cases in 2018 than in 2017, India's malaria burden still remains considerable at an estimated 6.7 million cases. ${ }^{1}$ Out of all the global Plasmodium vivax burden, $53 \%$ is in the WHO South-East Asia Region, India accounting for $47 \%$ and is a major cause of health burden in these countries. ${ }^{1} P$. vivax malaria is now known to cause considerable morbidity and mortality due to severe malaria. ${ }^{2}$ In addition, due to relapses $P$. vivax causes additional burden on disease burden and feeds transmission. Despite the problem of $P$. vivax, malaria control have hitherto focused more on $P$. falciparum. It is likely that this burden will increase in 2020 2021 due to diversion of public health attention towards COVID-19. At the same time, there is a potential for several cross-learnings between malaria and COVID-19. ${ }^{34}$ Nonetheless, $P$. vivax continues to be a pressing healthcare issue and may prove to be a challenge in India, which along with Indonesia and Pakistan accounts for $>80 \%$ of the global $P$. vivax burden. ${ }^{5}$ As per the Indian national statistics the country reported $\sim 338 \mathrm{~K}$ malaria cases in 2019 of which $\sim 181 \mathrm{~K}(53 \%)$ were caused by $P$. vivax. Among the top 20 districts with highest Annual Parasite Incidence (out of a total of 721 malarious districts) cases in five districts had $>70 \%$ burden due to $P$. vivax in 2019 . $^{6}$ This trend can seriously undermine the efforts of Indian government towards malaria

\section{Summary}

India reported 181,554 malaria cases caused by Plasmodium vivax in 2019 and WHO estimates point out that almost half of global vivax burden is in India.

- Current treatment of vivax malaria by 3 days of chloroquine and 14 days of low dose of primaquine suffers from poor compliance.

- The incomplete clearance of vivax reservoir pose a threat to India's and regional malaria elimination plans.

- Tafenoquine as an alternative to primaquine may overcome some of the challenges to malaria elimination.

elimination notwithstanding the highly impressive decline in India's disease burden.

\section{THE TWO DOMINANT MALARIA PARASITES}

$P$. falciparum and $P$. vivax both cause blood stage infections that can last up to years. ${ }^{7}$ The mechanisms of parasite growth such as asexual merozoites invading red blood cells, replicating every 48 hours and the acquisition of partial immunity result in complex infection dynamics. ${ }^{8}$ In addition to this, $P$. vivax has another mechanism for persisting that is, via the reservoir of hypnozoites, that lay dormant in the liver. After the introduction of $P$. vivax sporozoites into the blood, from an infected mosquito, some of the sporozoites become hypnozoites and lie dormant in the liver for as long as years until they get activated to initiate fresh blood-stage infections, and this cycle continues, much to the detriment of the patient. ${ }^{7}$ Reactivation of hypnozoites of $P$. vivax lead to blood-stage infections, known as relapses, are the distinctive feature between the two Plasmodium species. ${ }^{7}$

Artemisinin combination therapy (ACT) is the established therapeutic plan for P. falciparum (against schizonts) which targets bloodstage infection. However, ACT or chloroquine 
(CQ) alone do not suffice in treating P. vivax (or P. ovale) completely since they are not active against hypnozoites lying dormant in the liver. If left untreated, these hypnozoites increase the incidence of infection and this in turn feeds transmission. For $\sim 75$ years, since its discovery in the 1940s, primaquine (PQ) has been the only licensed drug in humans for the clearance of $P$. vivax hypnozoites. The radical treatment for $P$. vivax in India is treatment with CQ for 3 days, plus PQ for 14 days. ${ }^{6}$

There are several impediments to the complete and successful treatment of $P$. vivax malaria. A few notables are (1) poor compliance of the 14 day regime of PQ: since patients usually get symptomatic relief within a few days of starting CQ, they tend not to complete the PQ treatment plan of 14 days. ${ }^{9}$ Supervision of scheduled intake of $\mathrm{PQ}$ by healthcare workers is also far from adequate in India. $^{9}$ (2) Glucose-6-phosphate dehydrogenase (G6PD) deficiency: PQ can have major adverse effects by causing dose associated acute haemolytic anaemia in individuals with G6PD deficiency. ${ }^{5}$ Hence, WHO recommends G6PD testing before $\mathrm{PQ}$ administration as the best practice and standard radical treatment of daily $\mathrm{PQ}$ not to be given to patients who are G6PD deficient. ${ }^{10}$ National-level estimates of G6PD deficiency in India are not available but studies suggest that the average prevalence may be $\sim 9.8 \%$ in tribal populations and $\sim 7.3 \%$ in other groups. ${ }^{11}$ In India, there is higher prevalence of G6PD deficiency in the malarious states of Maharashtra, Odisha, Uttar Pradesh and Rajasthan. ${ }^{11}$ Indian national guidelines mandate testing for G6PD deficiency wherever possible, but in the absence of any reliable point of care test and the limitations of overstretched and underdeveloped healthcare systems in India, the actual deployment rate of these tests remains largely unknown. Monitoring of haemolysis and thus the drop in haemoglobin levels needs a vigilant healthcare system, especially in the backdrop of wide prevalence of anaemia in India. (3) PQ use contraindications in pregnant and lactating mothers leave aside a large proportion of malaria patients who are thus incompletely treated and remain susceptible to $P$. vivax relapses. (4) There remains an unknown burden of relapses and asymptomatic malaria including undetected $P$. vivax cases due to low parasitaemia in India as no nationwide data are available for either. Monitoring of $P$. vivax patients, not only for ensuring compliance to 14 days of PQ treatment, but also for development of relapses thus remains a huge systemic gap. (5) Drug resistance: the mechanism of resistance for eight aminoquinoline compounds like PQ has not been fully addressed in comparison to resistance patterns in CQ that are better studied and understood. ${ }^{12}$ Treatment failure (relapse occurrence) is usually confused as PQ resistance. There is no confirmed evidence of genuine resistance to $P Q$. Baird and Hoffman have published instances of $\mathrm{PQ}^{12}$ treatment failure in patients on 5 days of $15 \mathrm{mg}$ per day of PQ instead of the standard 14 days treatment with same dosages. ${ }^{12}$ Therefore, the above factors may continually fuel $P$. vivax transmission in India and threaten not only the country's objective of malaria elimination by 2030 but also regional plans of the same.

To circumvent some of the roadblocks listed above, it is proposed here that Indian national malaria elimination programme consider the safety validation under real-world conditions following G6PD testing and then possible inclusion of the antihypnozoite drug tafenoquine (TQ) that has been developed for $P$. vivax radical cure. This orally active 8-aminoquinoline was discovered in 1978 at the Walter Reed Army Institute of Research (WRAIR), USA. ${ }^{13} \mathrm{TQ}$ is a synthetic analogue of PQ as it differs in the presence of a methyl group and a phenoxy group at positions 4 and 5 , respectively, of the drug. It was first developed with a prophylactic intention by GlaxoSmithKline and WRAIR. WRAIR worked with the Central Drug Research Institute, Lucknow, India to test and validate TQ for radical cure (1982-1987) ${ }^{14}$ and later further advanced jointly by GlaxoSmithKline and the Medicines for Malaria Venture as a radical treatment for $P$. vivax infection. ${ }^{13}$ Currently, TQ is approved by the FDA (US Food and Drug Administration) and is being used in the USA under the brand name of Krintafel (150 mg tablets, GlaxoSmithKline) as radical cure for $P$. vivax and as a prophylactic (100 mg tablets, Sixty Degree Pharma) under the brand name Arakoda. It has also been approved by Therapeutics Goods Administration (TGA) in Australia since 2018 and since 2019 in Brazil (first among the malaria endemic countries) and Thailand under brand name Kozenis. Recently, Peru became the second Latin country to approve of TQ in January 2021.

\section{PHARMACODYNAMICS AND PHARMACOKINETICS OF TQ}

$\mathrm{TQ}$ is similar to $\mathrm{PQ}$ in drug activity against the preerythrocytic forms within the liver. In addition, it is potent against both asexual and sexual parasite forms in the blood. However, TQ differs from PQ due to its longer half-life, which supports its use as a single-dose drug. TQ shows extensive protein binding of $>99.5 \%$ and has a distribution volume of $\approx 1600 \mathrm{~L}$ for the prophylactic dose. PQ on the other hand shows protein binding of $75 \%$ and a volume of distribution of 150-250 L. Thus, with an oral clearance of $\approx 3 \mathrm{~L} /$ hours, TQ has an average terminal half-life of $\sim 15$ days as opposed to that of $\mathrm{PQ}$ which is 4-6 hours. ${ }^{15} \mathrm{PQ}$ activity is known to vary significantly with CYP2D6 genotype activity. However, there are no conclusive studies to demonstrate the dependence of TQ activity on CYP2D6 activity though some early studies ${ }^{16}$ indicate so but it is yet to be confirmed. According to a study by Paradkar in 2018, the impaired CYP2D6 $* 10$ allele prevalence was $19.2 \%$ in the Indian population ${ }^{17}$ which may have implications on eight aminoquinoline efficacy. While the effects of TQ on renal or hepatic impairment and their consequent effect on pharmacokinetics of $\mathrm{TQ}$ have not been studied, the pharmacokinetic profile of TQ remains unaffected by age, sex, ethnicity and bodyweight. ${ }^{18}$ Drug interaction studies have concluded that 
the pharmacokinetics of $\mathrm{TQ}$ were not affected on coadministration with $\mathrm{CQ}$, dihydroartemisinin-piperaquine or artemether-lumefantrine. ${ }^{18}$

\section{POSSIBLE MECHANISMS OF TQ ACTION AND G6PD DEFICIENCY}

Though the mechanism(s) of action responsible for TQ's antiplasmodial activities remain unknown, studies on protozoan parasites, including $P$. falciparum, have suggested that TQ may interfere with mitochondrial functions and lead to apoptotic-like death of the organism. It has also been suggested that $\mathrm{TQ}$ may also show its effect by inhibiting hematin polymerisation. ${ }^{19}$ In addition to its antiplasmodial activities, TQ causes red cell shrinkage and eryptosis or suicidal erythrocyte death, a process similar to apoptosis in nucleated cells. ${ }^{18} \mathrm{TQ}$ has also shown activity against sporogonic forms of $P$. vivax at doses of more than or equal to $25 \mathrm{mg} / \mathrm{kg} .{ }^{20}$

As an 8-aminoquinoline, TQ like $\mathrm{PQ}$ causes dosedependent, drug-induced haemolysis in individuals with G6PD deficiency, an X-linked enzyme deficiency thought to affect around 400 million people across the globe. ${ }^{21}$ Its slow elimination has a protracted oxidant effect and therefore TQ can be used in individuals whose G6PD enzyme activity is $>70 \%$ of normal. ${ }^{5}$ It is apparent that TQ usage will require G6PD testing that can quantify G6PD enzymatic activity. Herein lies the challenge for malaria control programmes, but this can be overcome by introducing widespread G6PD testing, in ways applicable to the field.

A reduction in haemoglobin of $>30.0 \mathrm{~g} / \mathrm{L}$, or $\geq 30 \%$ from baseline, or haemoglobin $<60.0 \mathrm{~g} / \mathrm{L}$ was the primary outcome in the Phase 3 supportive safety study of $\mathrm{CQ}+\mathrm{TQ}$ versus $\mathrm{CQ}+\mathrm{PQ}{ }^{22}$ The available $\mathrm{G} 6 \mathrm{PD}$ rapid qualitative tests in the market use a limit of $30 \%-40 \%$ of normal G6PD activity as a cut-off to define a subject as G6PD deficient ${ }^{9}$ and hence will not be applicable for TQ usage which needs a minimum of 70\% G6PD activity, in comparison to $\mathrm{PQ}$ which needs $30 \%$. $^{10}$ These values identify the G6PD deficient genotype in male hemizygotes and female homozygotes; the group at most risk of severe haemolysis with drug use. Heterozygous females who possess 30\%-80\% of normal G6PD enzyme activity (intermediate activity) exhibit results which are difficult to slot on qualitative tests as normal or deficient. ${ }^{10}$ The severity in reduction of haemoglobin documented after TQ exposure is dependent on the level of G6PD enzyme activity. The greatest decline has been observed in those with low G6PD activity such as hemizygous males and homozygous females besides those who are WHO class II variants. ${ }^{23}$ In India, the latter dominate. ${ }^{24}$ Finally, $\mathrm{TQ}$ is contraindicated for use in pregnant and lactating mothers, in breastfeeding infants and patients below the age of 16 years. TQ is contraindicated in pregnant and lactating women which could constitute a substantial proportion of population, and even if TQ is distributed with great coverage, a substantial proportion, as in the case of $\mathrm{PQ}$, will be left untreated. Under the national guidelines, $\mathrm{PQ}$ is contraindicated in infants and pregnant women. Follow-up of these groups is recommended under the programme and PQ administered post delivery, once the G6 PD status of the neonate is known. CYP2D6 is not assessed in the national programme. Clearly these are some gaps in the management of vivax malaria and risk of relapses. WHO recommends that G6PD deficient patients to be treated with $0.75 \mathrm{mg} / \mathrm{kg}$ body weight weekly over a period of 8 weeks. TQ should also not given in patients with a history of psychiatric disorders at doses higher than the approved dose or in patients with known hypersensitivity to 8 -aminoquinolines. ${ }^{13}$

\section{INTERNATIONAL TQ TRIALS}

Until today, $>30$ clinical studies/trials have been conducted using TQ as an antimalarial agent that targets both $P$. vivax relapses and $P$. falciparum. In 1998, the first successful clinical trial was reported. ${ }^{13}$ There are three key studies that have established single dose of $300 \mathrm{mg}$ of $\mathrm{TQ}$ as radical treatment of $P$. vivax malaria when in combination with the standard CQ regimen. These are:

- DETECTIVE, Part 1 (NCT01376167) ${ }^{25}$ : The Dose and Efficacy Trial Evaluating Chloroquine and Tafenoquine in Vivax Elimination Part 1. Single doses of $50,100,300$ and $600 \mathrm{mg}$ TQ and 3 days of CQ were compared with $\mathrm{PQ}$ at the dose of $15 \mathrm{mg} /$ day for 14 days and 3 days of $C Q$ and $C Q$ alone in the third arm.

- DETECTIVE, Part 2 (NCT01376167) ${ }^{26}$ : The Dose and Efficacy Trial Evaluating Chloroquine and Tafenoquine In Vivax Elimination Part 2. Single dose of 300 $\mathrm{mg} T \mathrm{~T}$ and 3 days of $\mathrm{CQ}$ was compared with $P Q$ at the dose of $15 \mathrm{mg} /$ day for 14 days and 3 days of CQ and $\mathrm{CQ}$ alone in the third arm.

- GATHER (NCT02216123) 22: The Global Assessment of Tafenoquine Hemolytic Risk assessed the effect of single dose of $300 \mathrm{mg} \mathrm{TQ}$ and $\mathrm{CQ}$ versus 14-day $\mathrm{PQ}$ and $\mathrm{CQ}$ on clinically relevant haemolysis $(\mathrm{Hb}$ decrease of $\geq 30 \%$ or $>30 \mathrm{~g} / \mathrm{L}$ from baseline or reduction of $\mathrm{Hb}$ below $60 \mathrm{~g} / \mathrm{L}$ ).

The details of the key studies on TQ have been summarised in table 1 and further, all studies on TQ have been collated and summarised in a review by Hounkpatin et $a l^{13}$ All the trials so far have suggested TQ to be a safe drug for regular use barring the contraindications.

\section{THE WAY FORWARD FOR TQ}

In light of the distinctive edge $\mathrm{TQ}$ has over $\mathrm{PQ}$ it is important that measures and mechanisms are devised to overcome the hurdles in deployment of TQ in India. Some notables are: (1) to resolve the issue of detection of G6PD enzyme activity via a portable point of care device that has been developed by SD BIOSENSOR. This product has been granted import permission by Ministry of Health and Family Welfare and is being marketed in India. Its clinical validation in India (Kolkata) has been completed and results are awaited. It is also under regulatory review by US FDA and AU TGA though it has been 
Table 1 Key tafenoquine trials

\begin{tabular}{|c|c|c|c|c|c|}
\hline S. no & Trial/study & Place/year & $\begin{array}{l}\text { Total no. of } \\
\text { participants }\end{array}$ & $\begin{array}{l}\text { Recurrence free rate } \\
\text { of } C Q+P Q\end{array}$ & $\begin{array}{l}\text { Recurrence free rate of CQ+TQ } \\
\text { (single dose) }\end{array}$ \\
\hline 1. & $\begin{array}{l}\text { DETECTIVE Part } 1 \\
\text { NCT01376167 } \\
\text { Phase } \mathrm{Ilb} / \mathrm{III} \text { trial }^{25}\end{array}$ & $\begin{array}{l}\text { Brazil } \\
\text { Peru } \\
\text { India } \\
\text { Thailand } \\
\text { 2011-2013 }\end{array}$ & 329 total & $\begin{array}{l}77 \% \\
(95 \% \mathrm{Cl} 63 \% \text { to } 87 \%)\end{array}$ & $\begin{array}{l}50 \mathrm{mg}: 58 \%(95 \% \mathrm{Cl} 43 \% \text { to } 70 \%) \\
100 \mathrm{mg}: 54 \%(95 \% \mathrm{Cl} 40 \% \text { to } 66 \%) \\
300 \mathrm{mg}: 89 \%(95 \% \mathrm{Cl} 77 \% \text { to } 95 \%) \\
600 \mathrm{mg}: 92 \%(95 \% \mathrm{Cl} 80 \% \text { to } 97 \%)\end{array}$ \\
\hline 2. & $\begin{array}{l}\text { DETECTIVE Part } 2 \\
\text { NCT01376167 } \\
\text { Phase III Trial }^{26}\end{array}$ & $\begin{array}{l}\text { Brazil } \\
\text { Peru } \\
\text { Colombia } \\
\text { Thailand } \\
\text { Philippines } \\
\text { Ethiopia } \\
\text { 2015-2016 }\end{array}$ & 522 total & $\begin{array}{l}70 \%(95 \% \mathrm{Cl} 60 \% \text { to } \\
77 \%)\end{array}$ & $62 \%(95 \% \mathrm{Cl} 55 \%$ to $69 \%)$ \\
\hline 3. & $\begin{array}{l}\text { GATHER } \\
\text { NCT02216123 } \\
\text { Phase III Trial }^{22}\end{array}$ & $\begin{array}{l}\text { Brazil } \\
\text { Colombia } \\
\text { Ethiopia } \\
\text { Peru } \\
\text { Thailand } \\
\text { Vietnam } \\
\text { 2014-2016 }\end{array}$ & 251 total & $\begin{array}{l}75 \%(95 \% \mathrm{Cl} 64 \% \text { to } \\
83 \%)\end{array}$ & $73 \%(95 \% \mathrm{Cl} 65 \%$ to $79 \%)$ \\
\hline
\end{tabular}

$\mathrm{CQ}$, chloroquine; $\mathrm{PQ}$, primaquine; $\mathrm{TQ}$, tafenoquine.

already approved by the Global Fund Expert Review Panel. ${ }^{27}$ Approval for TQ use under Indian national programme is under review (2) to impart additional training to healthcare workers to use the point-of-care test before TQ usage and PQ use as per national guidelines. Compliance can be ensured by Directly Observed Therapy as is being done in other disease elimination programmes like Tuberculosis and Lymphatic Filariasis. (3) to make provisions for additional costs of TQ due to mandatory G6PD testing to Indian healthcare system though these will decrease as the drug begins to be used widely. The G6PD test and TQ tablet together will cost $\sim$ US\$ 1.40 which is at par with the cost of PQ that sells at $\sim$ US $\$ 1$. The price in India and other endemic countries is volume-based assuming an annual production of 1 million doses. The Indian costs is a not-for-profit price based on manufacturing costs alone (personal communication). Undoubtedly, the costing is of lower significance in context of the aimed elimination of malaria from India. It is vital to reduce $P$. vivax transmission by clearing reservoirs of parasites that cycle via relapses and thus to protect those for whom radical cure with either $P Q$ or TQ is contraindicated.

In conclusion, $P$. vivax infection remains endemic in India despite huge gains in its control over the past two decades. Data suggest that the elimination of $P$. vivax foci can be achieved but not in less than 3 years, compared with the 1 year for $P$. falciparum. ${ }^{28}$ Hence, India needs to deploy all new malaria control tools like G6PD testing and TQ to continue to stem this scourge. The current treatment protocol of $\mathrm{CQ}$ plus $\mathrm{PQ}$ for 14 days has substantial concerns attached to its poor compliance and possible drug resistance. Due to this, TQ provides a good alternative and maybe considered further in India. The adoption of $\mathrm{TQ}$ in the current Indian healthcare scenario may address the excessive burden India bears of world's $P$. vivax.

Acknowledgements The authors thank Department of Science and Technology for the JC Bose fellowship to AS.

Contributors AS conceived the idea. SSA did extensive literature reviews and drafted the manuscript. MR made important additions. All authors wrote the paper. All authors read and approved the final manuscript.

Funding The authors have not declared a specific grant for this research from any funding agency in the public, commercial or not-for-profit sectors.

Competing interests None declared.

Patient consent for publication Not required.

Provenance and peer review Not commissioned; externally peer reviewed.

Data availability statement There is no data in this work.

Open access This is an open access article distributed in accordance with the Creative Commons Attribution Non Commercial (CC BY-NC 4.0) license, which permits others to distribute, remix, adapt, build upon this work non-commercially, and license their derivative works on different terms, provided the original work is properly cited, appropriate credit is given, any changes made indicated, and the use is non-commercial. See: http://creativecommons.org/licenses/by-nc/4.0/.

ORCID iD

Amit Sharma http://orcid.org/0000-0002-3305-0034

\section{REFERENCES}

1 World malaria report 2019, Geneva. Available: https://www.who.int/ publications/i/item/9789241565721 [Accessed 30 Oct 2020].

2 Matlani M, Kojom LP, Mishra N, et al. Severe vivax malaria trends in the last two years: a study from a tertiary care centre, Delhi, India. Ann Clin Microbiol Antimicrob 2020;19:49 https://doi.org/10.1186/ s12941-020-00393-9

3 Rahi M, Das P, Sharma A. COVID-19 mitigation steps provide a blueprint for malaria control and elimination. Am J Trop Med Hyg 2020;103:28-30. 
4 Rahi M, Baharia RK, Das P, et al. Overlaying COVID-19 mitigation plans on malaria control infrastructures. Trans $R$ Soc Trop Med Hyg 2020:1-3.

5 Watson J, Taylor WRJ, Bancone G, et al. Implications of current therapeutic restrictions for primaquine and tafenoquine in the radical cure of vivax malaria. PLoS Negl Trop Dis 2018;12:e0006440.

6 National Vector Borne Disease Control Programme. Available: https://nvbdcp.gov.in/ [Accessed 30 Oct 2020].

7 Mueller I, Galinski MR, Baird JK, et al. Key gaps in the knowledge of Plasmodium vivax, a neglected human malaria parasite. Lancet Infect Dis 2009;9:555-66.

8 Kerlin DH, Gatton ML. A simulation model of the within-host dynamics of Plasmodium vivax infection. Malar J 2015;14:51.

9 Saravu K, Kumar R, Ashok H, et al. Therapeutic assessment of Chloroquine-Primaquine combined regimen in adult cohort of Plasmodium vivax malaria from primary care centres in southwestern India. PLoS One 2016;11:e0157666.

10 World Health Organization. Guide to G6PD Deficiency rapid diagnostic testing to support $P$. vivax radical cure, 2018. Available: https://apps.who.int/iris/bitstream/handle/10665/272971/ 9789241514286-eng.pdf?ua=1 [Accessed 4 Nov 2020].

11 Shah II, Jarullah J, Jarullah B. Prevalence of glucose-6-phosphate dehydrogenase (G6PD) deficiency in India: a systematic review. $A B B$ 2018;09:481-96.

12 Baird JK, Hoffman SL. Primaquine therapy for malaria. Clin Infect Dis 2004:39:1336-45

13 Hounkpatin AB, Kreidenweiss A, Held J. Clinical utility of tafenoquine in the prevention of relapse of Plasmodium vivax malaria: a review on the mode of action and emerging trial data. Infect Drug Resist 2019;12:553-70.

14 Dhar MM. Synthesis and screening of new antimalarial drugs. Central Drug Research Institute. Lucknow. Annual rept, 1987. Available: https://apps.dtic.mil/sti/citations/ADA192948 [Accessed 20 Nov 2020].

15 Miller AK, Harrell E, Ye L, et al. Pharmacokinetic interactions and safety evaluations of coadministered tafenoquine and chloroquine in healthy subjects. Br J Clin Pharmacol 2013;76:858-67.

16 Marcsisin SR, Sousa JC, Reichard GA, et al. Tafenoquine and NPC-1161B require CYP 2D metabolism for anti-malarial activity: implications for the 8-aminoquinoline class of anti-malarial compounds. Malar J 2014;13:2 https://doi.org/10.1186/1475-287513-2
17 Paradkar MU, Shah SAV, Dherai AJ, et al. Distribution of CYP2D6 genotypes in the Indian population - preliminary report. Drug Metab Pers Ther 2018;33:141-51.

18 Green JA, Mohamed K, Goyal N, et al. Pharmacokinetic interactions between tafenoquine and dihydroartemisinin-piperaquine or artemether-lumefantrine in healthy adult subjects. Antimicrob Agents Chemother 2016;60:AAC.01588-16-7332.

19 Crockett M, Kain KC. Tafenoquine: a promising new antimalarial agent. Expert Opin Investig Drugs 2007;16:705-15.

20 Ponsa N, Sattabongkot J, Kittayapong P, et al. TransmissionBlocking activity of tafenoquine (WR-238605) and artelinic acid against naturally circulating strains of Plasmodium vivax in Thailand. Am J Trop Med Hyg 2003;69:542-7.

21 Recht J, Ashley EA, White NJ. Use of primaquine and glucose-6phosphate dehydrogenase deficiency testing: divergent policies and practices in malaria endemic countries. PLoS Negl Trop Dis 2018;12:e0006230.

22 Llanos-Cuentas A, Lacerda MVG, Hien TT, et al. Tafenoquine versus primaquine to prevent relapse of Plasmodium vivax malaria. $N$ Engl $J$ Med 2019;380:229-41.

23 Rueangweerayut R, Bancone G, Harrell EJ, et al. Hemolytic Potential of Tafenoquine in Female Volunteers Heterozygous for Glucose6-Phosphate Dehydrogenase (G6PD) Deficiency (G6PD Mahidol Variant) versus G6PD-Normal Volunteers. Am J Trop Med Hyg 2017;97:702-11.

24 Mohanty D, Mukherjee MB, Colah RB. Glucose-6-Phosphate dehydrogenase deficiency in India. Indian J Pediatr 2004;71:525-9.

25 Llanos-Cuentas A, Lacerda MV, Rueangweerayut R, et al. Tafenoquine plus chloroquine for the treatment and relapse prevention of Plasmodium vivax malaria (detective): a multicentre, double-blind, randomised, phase 2B dose-selection study. Lancet 2014;383:1049-58.

26 Lacerda MVG, Llanos-Cuentas A, Krudsood S, et al. Single-Dose Tafenoquine to prevent relapse of Plasmodium vivax malaria. N Engl J Med 2019;380:215-28.

27 PATH. Path and SD biosensor announce partnership to advance diagnostic test critical for malaria treatment and elimination. Available: https://www.path.org/media-center/path-and-sdbiosensor-announce-partnership/ [Accessed 20 Nov 2020]

28 Pampana E. A textbook of malaria eradication. 2nd edn. London: Oxford University Press, 1969. 